\title{
The Characterization of Linear Polyethylene SRM 1475. VII. Differential Refractive Index of Polyethylene Solutions
}

\author{
Herman L. Wagner \\ Institute for Materials Research, National Bureau of Standards, Washington, D.C. 20234
}

(December 15, 1971)

\begin{abstract}
The value of $d n / d c$ for polyethylene in 1-chloronaphthalene at $135^{\circ} \mathrm{C}$, required for the determination of molecular weight by light scattering, was found to vary with molecular weight. Similar changes were found in 1,2,4-trichlorobenzene, the gel permeation chromatograph solvent. The absolute value of $d n / d c$ decreases by about 2 percent as the polymer molecular weight increases from 12,000 to 110,000 .
\end{abstract}

Key words: 1-chloronaphthalene; $d n / d c$; differential refractive index; refractometer; refractive index; 1,2,4-trichlorobenzene.

\section{Introduction}

Since the change of refractive index with concentration, $d n / d c$ (differential refractive index), enters as a squared term in the light scattering equation, its accuracy is of considerable importance for obtaining reliable values of molecular weight of polymers. The first determination of $d n / d c$ of polyethylene in 1-chloronaphthalene (table 1) found in the literature was by Nichols and was reported by Billmeyer [1]. ${ }^{1}$ It was measured at $90{ }^{\circ} \mathrm{C}$ and $125^{\circ} \mathrm{C}$ using a divided cell technique, giving values of $-0.199 \mathrm{ml} / \mathrm{g}$ and $-0.191 \mathrm{ml} / \mathrm{g}$ respectively. The latter value is the one most often quoted. Kobayashi, Chitale, and Frank [2], using an interferometer technique, obtained a some- what lower value at $90^{\circ}$, namely -0.183 . Nicholas [3] found a very low value $\left(-0.257\right.$ at $\left.125^{\circ} \mathrm{C}\right)$ using a Rayleigh differential refractometer at concentrations of 0.15 to $0.7 \mathrm{~g} / 100 \mathrm{ml}$. This result seems to be completely out of line with the other values reported and may be due to the greater errors incurred working at low concentrations. The use of such low concentrations would appear to be unnecessary inasmuch as $d n / d c$ is found to be constant at the concentrations used in this work, which range from $0.5 \mathrm{~g} / 100 \mathrm{ml}$ to $4 \mathrm{~g} / 100 \mathrm{ml}$.

Most of the other literature values fall in the range of -0.188 to $-0.199[4,5,6]$. The recent data are those of Drott and Mendelson [7], Chiang and Rhodes [8] and Benoit et al. [9]. Drott and Mendelson provide considerable detail about their procedure, which appears to

TABLE 1. Literature values of $\mathrm{dn} / \mathrm{dc}$ for polyethylene in 1-chloronaphthalene

\begin{tabular}{|c|c|c|c|c|c|c|c|c|}
\hline \multicolumn{9}{|c|}{$d n / d c$ in $\mathrm{ml} / \mathrm{g}$} \\
\hline Refs. & 1 & 2 & 3 & 6 & 22 & 7 & 8 & 9 \\
\hline \multicolumn{9}{|c|}{ Temp. ${ }^{\circ} \mathrm{C}$} \\
\hline $\begin{array}{l}90 \\
99.5 \\
104.5 \\
105 \\
109 \\
114 \\
120 \\
125 \\
127 \\
128 \\
135 \\
139 \\
140 \\
145\end{array}$ & -0.199 & -0.183 & -0.257 & -0.188 & $\begin{array}{r}-0.198 \\
-.195\end{array}$ & $\begin{array}{r}-0.195 \\
-.191\end{array}$ & $\begin{array}{r}-0.1924 \\
-.1927 \\
-.1934 \\
-.1927 \\
-.1917 \\
-.1911 \\
\\
-.190\end{array}$ & $\begin{array}{r}-0.1957 \\
-.1967 \\
-.1955 \\
-.1956 \\
-.1961 \\
-.1967\end{array}$ \\
\hline
\end{tabular}

${ }^{1}$ Figures in brackets indic ate the literature references at the end of this paper. 
be thorough and careful, and obtained a value of -0.191 at $140{ }^{\circ} \mathrm{C}$ and -0.195 at $125^{\circ} \mathrm{C}$. Chiang believes his values for a low molecular weight branched sample of -0.195 at $80^{\circ} \mathrm{C}[10]$ are consistent with his values for higher molecular weights which range from -0.193 at $100{ }^{\circ} \mathrm{C}$ to -0.190 at $135^{\circ} \mathrm{C}$. Benoit et al. measured $d n / d c$ between $141{ }^{\circ} \mathrm{C}$ and $150^{\circ} \mathrm{C}$ finding values about $2 \frac{1}{2}$ percent higher than those of Chiang and Billmeyer. The change in $d n / d c$ with temperature is insignificant in this temperature range.

In view of the uncertainties described above and the importance of accurate values of $d n / d c$, it appeared necessary to make as accurate a determination as possible for the Standard Reference Materials Program. It soon became evident that $d n / d c$ was to some extent a function of molecular weight. This may account for some of the discrepancies in the literature but these could not be readily resolved because in most cases no characterization is provided for the polyethylene used in the $d n / d c$ measurement. It was also necessary to measure the variation with molecular weight in 1,2,4-trichlorobenzene since this solvent is used in gel permeation chromatography with the assumption that $d n / d c$ is constant.

\section{Experimental Procedure}

The determination of the change of refractive index with concentration is most conveniently accomplished by a differential refractometer. The instrument employed here was the image displacement type, in which light passes through a cell consisting of two adjacent prismatic compartments, one containing solvent, the other dilute solution. It may be easily shown that in the limit as the difference $\Delta n$ between the refractive index of solution and of solvent becomes small, the displacement $\Delta d$ of the imaged light source from its position with pure solvent in both compartments of the cell becomes proportional to $\Delta n$, i.e.,

$$
\Delta n=k \Delta d
$$

where $k$ is the proportionality constant and is determined by calibration with a substance of known refractive index.

\subsection{Optical System}

The optical system, consisting of the elements shown in figure 1 , is mounted on an optical bench 125 $\mathrm{cm}$ long. Light from an air cooled mercury lamp passes

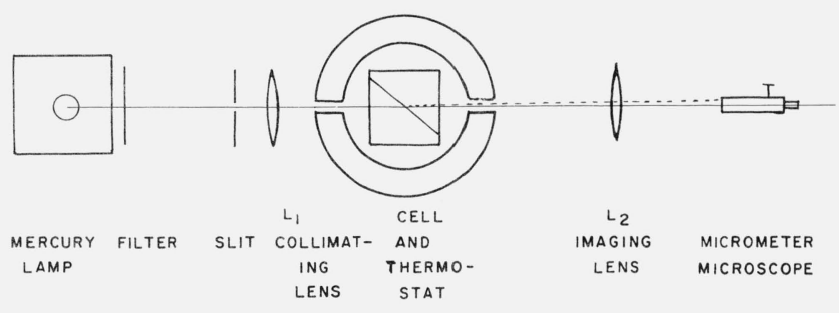

FigURE 1. Optical system, schematic. through a combination of filters which transmits green monochromatic light at $5460 \AA$. This light enters a slit, passes through the collimating lens, $L_{1}$, then through the cell, where the deviation due to the refractive index difference takes place. The displaced slit, imaged by the lens, $L_{2}$, is observed with a micrometer eyepiece having a $10 \mathrm{~mm}$ scale and a drum divided to $0.01 \mathrm{~mm}$. The entire optical system is carefully aligned so that the collimated beam is normal to the face of the cell. The system was stable in that once the optical components were fixed the reading did not change over a period of several days with a given solvent in both compartments of the cell.

\subsection{Glass Cell}

The sample cell, supplied commercially $[11]^{2}$ is a sinter fused Pyrex optical cell $15 \mathrm{~mm}$ square with plane parallel windows. The partition is set at such an angle that the light beam forms an angle of incidence of approximately $69^{\circ}$ with the normal to the surface of the partition. This cell is provided with a fused top with openings which are closed by Teflon stoppers, thus eliminating the problem of evaporation which in the past has caused troublesome temperature gradients at high temperatures.

\subsection{Cell Holder}

In order to achieve temperature stability over long periods of time and to keep the temperature difference between the two compartments of the cell down to a few hundredths of a degree, considerable care was necessary in the design of the cell holder. As in the apparatus discussed by Benoit et al. [9], the cell is set into a rectangular opening in the center of a cylindrical aluminum block, 4 in in diameter and 5 in high (fig. 2) containing a $\frac{3}{8}$ in hole for passage of the light beam. Aluminum 1100 was used because of its superior heat conductivity. The aluminum block is positioned by three bakelite pins inside a $\frac{1}{3}$ in thick brass shell of 5 in diameter, leaving a half inch air space to minimize heat loss. Both the aluminum block and the brass shell are heated by coils of wire embedded in silicone rubber. Additional heat is supplied by means of four rod heaters inserted into holes in the block and by another coil heater, also embedded in silicone rubber, underneath the brass shell. The temperature of the cell holder is maintained by a thermistor temperature controller. The entire assembly is insulated by a laminate composed of eight layers of balsa wood alternating with aluminum foil. Short term temperature fluctuations of the aluminum block were of the order of $0.001{ }^{\circ} \mathrm{C}$. Drift during a set of measurements was no greater than $0.01^{\circ} \mathrm{C}$.

Brice [12] recommends that the temperature difference between solvent and solution should be no greater than $0.01{ }^{\circ} \mathrm{C}$. Attempts to measure this difference by simply inserting thermocouples into each

${ }^{2}$ Certain commercial equipment, instruments, or materials are identified in this paper in order to adequately specify the experimental procedure. In no case does such identification imply recommendation or endorsement by the National Bureau of Standards, nor does it imply that the material or equipment identified is necessarily the best available for the purpose. 


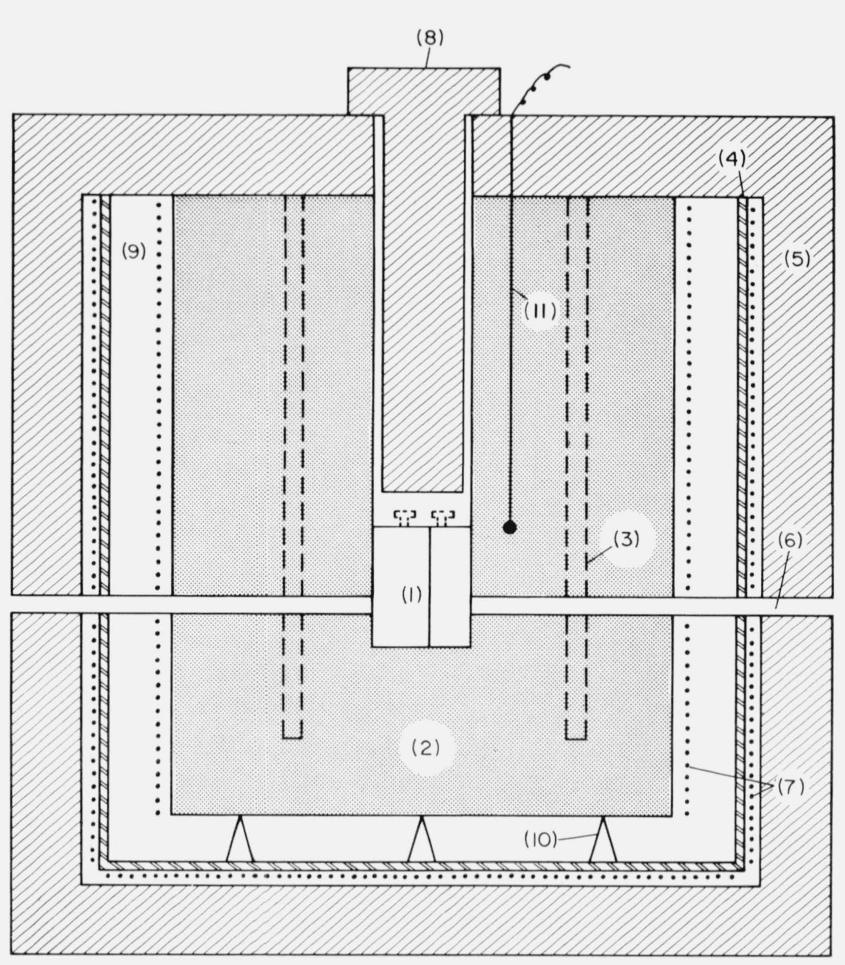

FigURE 2. Heating block for cell.

(1) Divided cell. (2) aluminum cylinder, (3) cartridge heaters, (4) brass shell, (5) balsa woodaluminum foil laminate, (6) opening for light path. (7) heaters embedded in silicone rubber, (8) balsa wood cap, (9) air space, (10) bakelite positioning pins, (11) thermistor.

compartment were unsuccessful, probably because of heat loss through the openings for the thermocouple leads and through the leads themselves. In view of the construction described above it is doubtful that a significant difference existed. In any case the effect of such a difference would be cancelled since measurements were made first with solution on one side and solvent on the other and again with solution and solvent reversed.

\section{Materials}

\subsection{Solvents}

Reagent grade 1-chloronaphthalene was double distilled, center cuts being taken each time. Observ- able impurities were less than 0.05 percent by gas liquid chromatography. The 1,2,4-trichlorobenzene, technical grade, was not further purified and 0.05 percent Ionol (2,6-di-tert.-butyl-4-methylphenol) was added as an antioxidant in order to use the same material used in the gel permeation apparatus [13]. Gas liquid chromatography revealed only a single major peak containing at least 99 percent of the material.

\subsection{Polymers}

Measurements of $d n / d c$ were made on several polyethylenes. They are: (1) SRM 1475, the linear polyethylene standard reference material described previously [14]; (2) fractions of SRM 1475 obtained by column extraction of this polyethylene [15]; (3) SRM 1476 , the branched polyethylene standard reference material. The available data are provided in the certificate for this material. Additional details will be given in a forthcoming publication: (4) fraction R 1201-7 is a linear polyethylene supplied by the Monsanto Chemical Company; (5) AC-6 is a polyethylene wax obtained from the Allied Chemical Corporation.

The number average molecular weights of these materials were obtained in various ways, as indicated in tables 2 and 3. Some were obtained by direct measurement by osmometry [16]; others were determined by gel permeation chromatography (G.P.C.) [13]. The number average molecular weights of fractions $12 x$ and $7 \mathrm{y}$ were estimated from molecular weight measurements made on other fractions prepared by the same process. For three of the samples (AC-6, R 1201-7, and SRM 1476), the values supplied by the manufacturer were used.

\section{Procedure}

For each concentration two readings of the displacement of the light beam were made. The first was taken with the solvent on one side and solution on the other and another reading was taken with these reversed. One-half the difference between the two readings multiplied by the calibration constant gave the value of the refractive index difference $\Delta n$. This is similar to the procedure of Brice and Halwer [12] ex-

TABLE 2. $\mathrm{dn} / \mathrm{dc}$ of Polyethylenes in 1-Chloronaphthalene at $135{ }^{\circ} \mathrm{C}$

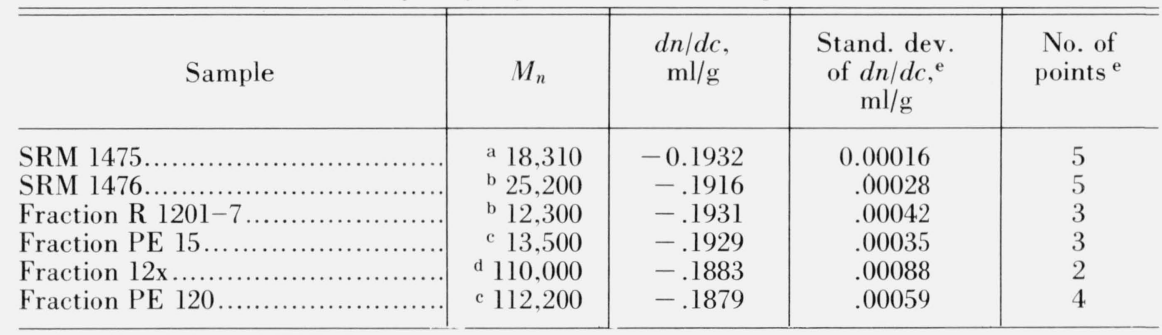

a Value obtained from Gel Permeation Chromatography [13].

Value provided by manufacturer.

Determined by osmometry [16].

d Estimated as described in text.

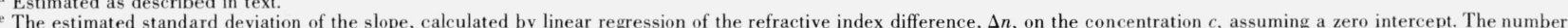
of points in each regression line is shown in column 5.

For convenience all standard deviations are given to two significant figures, with no implication that such precision is warranted. 
TABle 3. $\mathrm{dn} / \mathrm{dc}$ of Polyethylenes in 1,2,4-Trichlorobenzene at $135^{\circ} \mathrm{C}$

\begin{tabular}{|c|c|c|c|c|}
\hline Sample & $M_{n}$ & $\begin{array}{c}d n / d c \\
\mathrm{ml} / \mathrm{g}\end{array}$ & $\begin{array}{l}\text { Stand. dev. } \\
\text { of } d n / d c,{ }^{\mathrm{d}} \\
\mathrm{ml} / \mathrm{g}\end{array}$ & $\begin{array}{l}\text { No. of } \\
\text { points }\end{array}$ \\
\hline 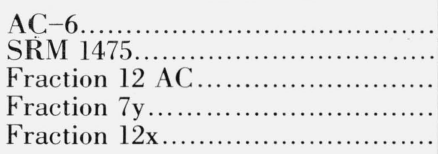 & $\begin{array}{r}\text { b } 2,000 \\
\text { a } 18,310 \\
\text { a } 34,800 \\
\text { c } 77,000 \\
\text { c } 110,000\end{array}$ & $\begin{array}{r}-0.1085 \\
-.1085 \\
-.1082 \\
-.1073 \\
-.1063\end{array}$ & $\begin{array}{r}0.00028 \\
.00015 \\
.00019 \\
.00038 \\
.00014\end{array}$ & $\begin{array}{l}3 \\
5 \\
3 \\
3 \\
4\end{array}$ \\
\hline
\end{tabular}

${ }^{\text {a }}$ Value obtained from Gel Permeation Chromatography [13]

b Approximate value, supplied by manufacturer.

b Approximate value, supplied by
${ }^{c}$ Estimated as described in text.

c Estimated as described in text.

of points in each regression line is shown in column 5 .

For convenience all standard deviations are given to two significant figures, with no implication that such precision is warranted.

cept that since it is not possible, as in their apparatus, to rotate our cell housing because of its large bulk, the cell is kept fixed and the contents reversed. Readings with solvent on both sides were made occasionally to make certain that the beam's position through the center of the cell had not shifted.

Solutions were made up by weight, and concentrations were calculated from measurements of solvent densities and partial specific volumes. The densities at $135{ }^{\circ} \mathrm{C}$ of 1-chloronaphthalene and 1,2,4-trichlorobenzene were found to be $1.095 \mathrm{~g} / \mathrm{ml}$ and $1.315 \mathrm{~g} / \mathrm{ml}$ respectively. The partial specific volumes were approximated from measurements of the change in density on dissolving the polymer to specified concentrations. The values obtained were $1.29 \mathrm{ml} / \mathrm{g}$ in 1-chloronaphthalene at a concentration of $0.03 \mathrm{~g} / \mathrm{ml}$ and $1.30 \mathrm{ml} / \mathrm{g}$ in $1,2,4$ trichlorobenzene at a concentration of $0.01 \mathrm{~g} / \mathrm{ml}$. It was assumed that at the low concentrations employed here the partial specific volume is constant, so that the volume increase on dissolving polymer is equal to the weight of the polymer multiplied by this approximate partial specific volume. The polymer was dissolved in the solvent at $140^{\circ} \mathrm{C}$ and about $1.5 \mathrm{ml}$ was transferred by a heated hypodermic syringe to the cell. The compartment was not cleaned and dried when its content was changed but was thoroughly rinsed beforehand with solvent and solution of the new concentration. A period of at least $15 \mathrm{~min}$ was allowed after transfer for temperature equilibration before readings were taken. The standard error (15 readings) was about $2 \times 10^{-6}$ in $\Delta n$ or about 0.2 percent. The least square slopes computed from these data show a standard deviation of the slope of from 0.1 to 0.5 percent, as shown in tables 2 and 3 . The standard deviation of the slope for the standard reference sample is about 0.1 percent.

No refractive index data at $135^{\circ} \mathrm{C}$ are available for calibration of differential refractometers. We therefore calibrated our instrument with aqueous solutions of NBS sucrose at $25^{\circ} \mathrm{C}$ and assumed the calibration did not change with temperature. The most likely cause for a change in calibration would be a change in the angle of the glass partition of the cell. Measurements in a cell similar to ours by Benoit et al. [9] of sodium chloride solutions up to $70^{\circ} \mathrm{C}$ did not reveal any changes with temperature.

The partial specific volume of sucrose in water was taken as $0.618 \mathrm{ml} / \mathrm{g}$ at $25^{\circ} \mathrm{C}$ [19]. The value of 0.1429 $\mathrm{ml} / \mathrm{g}$ for $d n / d c$ at $5460 \AA$ at $25^{\circ} \mathrm{C}$, obtained by Norberg and Sundeloff [18], was employed in the calibration of the apparatus. This value agrees very well with the results of other authors [19-21]. Bodmann [21] has shown that $d n / d c$ is constant up to concentrations of at least $0.025 \mathrm{~g} / \mathrm{ml}$. We found that the displacement $\Delta d$ of the light beam is linear with concentration for concentrations as high as $0.04 \mathrm{~g} / \mathrm{ml}$ and displacements up to $5 \mathrm{~mm}$, the limit of our instrument scale. The calibration constant $k$ for our instrument was found to be $1.1417 \times 10^{-3}$ refractive index units per $\mathrm{mm}$ deflection, with a standard deviation of 0.1 percent.

\section{Results and Discussion}

The values of $d n / d c$ for various polyethylenes in 1chloronaphthalene are listed in table 2 . The value for the linear sample, SRM 1475 at $135^{\circ} \mathrm{C}$ is $-0.193 \mathrm{ml} / \mathrm{g}$ and for the branched sample, SRM 1476, is -0.192 . The numbers fall into two groups: values of -0.192 to -0.193 for low number average molecular weights $(11,000-25,000)$ and a decidedly higher value, -0.188 for the higher molecular weights. In order to obtain a better idea of the molecular weight dependence and to determine whether gel permeation chromatography intensities need to be corrected for molecular weight, $d n / d c$ was measured in 1,2,4-trichlorobenzene over a range of molecular weights. These are enumerated in table 3 and a plot of these values against $1 / M_{n}$ is shown in figure 3. The change in $d n / d c$ in going from an $M_{n}$ of 12,000 to 110,000 is about the same in both solvents, a decrease of about 2 percent in absolute value. Several

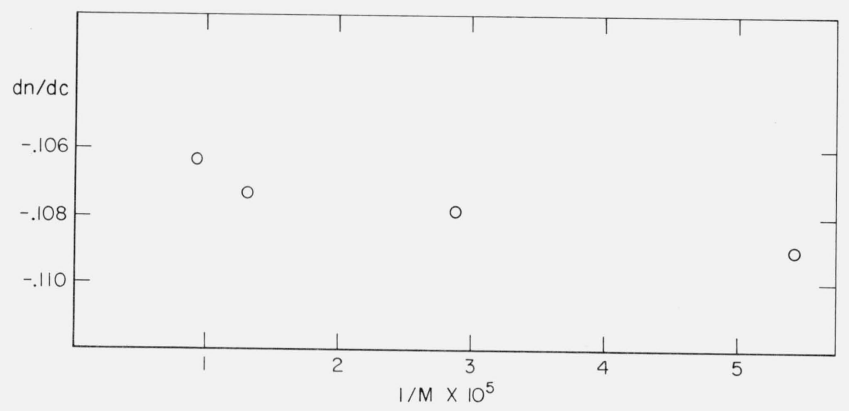

Figure 3. Differential refractive index in 1,2,4-trichlorobenzene. 
factors contribute to the belief that this is a real change. It is outside the limits of error of the determination, for which the standard deviation is of the order of 0.5 percent. Different fractions of the same molecular weight, such as $12 x$ and PE 120 in one case, and R 1201-7 and PE 15 for another, the latter two coming from different starting polymers, have the same values of $d n / d c$. The infrared spectra of the whole polymer SRM 1475 and a high molecular weight fraction, showing a smaller $d n / d c$, are similar, indicating the absence of some chemical group which might account for the difference in $d n / d c$.

Unfortunately it was not possible to measure $d n / d c$ for fractions of $M_{n}$ greater than 110,000 because of the difficulties of handling the extremely high viscosities of these fractions at the concentrations needed to give meaningful results. For most determinations concentrations ran between 0.5 to $4 \mathrm{~g} / 100 \mathrm{ml}$ but were limited to no greater than $2 \mathrm{~g} / 100 \mathrm{ml}$ for the high molecular weight samples.

\section{Conclusion}

Because $d n / d c$ changes with molecular weight, it is necessary to use the correct value of $d n / d c$ in light scattering work, as is done in Paper VIII of this series [23]. Although 1-chloronaphthalene measurements were not made for the intermediate molecular weight range, the measurements in trichlorobenzene are extensive enough to show that $d n / d c$ changes continually so that interpolation should provide sufficiently precise values for the former solvent. No data are available, however, at number averages greater than 110,000 , and since it can not be assumed that the absolute value of $d n / d c$ decreases without limit, the value at high molecular weights is taken, for the present, as constant at $-0.188 \mathrm{ml} / \mathrm{g}$ in 1-chloronaphthalene.

\section{References}

[1] Billmeyer, F., J. Am. Chem. Soc. 75, 6118 (1953).

[2] Kobayashi, T., Chitale, A., and Frank, H. P., J. Polymer Sci. 24, 156 (1957).

[3] Nicolas, L., J. Polymer Sci. 29, 191 (1958).

[4] Chiang, R., J. Polymer Sci. 36, 91 (1959).

[5] Duch, E. and Küchler, L., Z. Electrochem. 60, 218 (1956).

[6] Trementozzi, Q. A.. J. Polymer Sci. 36, 113 (1959).

[7] Drott, E. E. and Mendelson, R. A., Polymer Letters 2, 187 (1964).

[8] Chiang, R. and Rhodes, J. H., Polymer Handbook, Editors J. Brandrup and E. D., Immergut, p. 14-282, (Interscience, 1966).

[9] Ehl, J., Louchaux, C., Reiss, C., and Benoit, H., Makromol. Chem. 75, 35 (1964).

[10] Chiang, R., J. Polymer Sci. C8, 295 (1965).

[11] Phoenix-Precision Optical Company, Philadelphia, Pa.

[12] Brice, B. A., and Halwer, M., J. Optical Soc. of America 41, 1033 (1951).

[13] Ross, G. S. and Frolen, L. J., J. Res. Nat. Bur. Stand (U.S.)., 76A, (Phys. and Chem.), No. 2, 163-170 (Mar--Apr. 1972). Paper X of this series.

[14] Hoeve, C. A. J., Wagner, H. L., and Verdier, P. H., J. Res. Nat. Bur. Stand. (U.S.)., 76A, (Phys. and Chem.), No. 2, 137-140 (Mar.-Apr. 1972). Paper I of this series.

[15] Christensen, R. G., J. Res. Nat. Bur. Stand. (U.S.)., 76A, (Phys. and Chem.), No. 2, 149-150 (Mar--Apr. 1972). Paper VI of this series.

[16] Brown, J. E. and Verdier, P. H., J. Res. Nat. Bur. Stand. (U.S.), 76A, (Phys. and Chem.), No. 2, 161-163 (Mar.-Apr. 1972). Paper IX of this series.

[17] Bates, F. J., et al., NBS Circular C440 (May 1, 1942).

[18] Norberg, P. H. and Sundelof, L. A., Makromol. Chem. 77, 77 (1964).

[19] Gosting, L. J. and Morris, M. S., J. Am. Chem. Soc. 71, 1998 (1949).

[20] Maron, S. H. and Lou, R. L. H., J. Phys. Chem. 59, 231 (1955).

[21] Bodmann, O., Chemie-Ing.-Tech. 29, 468 (1957).

[22] Tung, L. H., J. Polymer Sci. 36, 287 (1959).

[23] Frolen, L. J., Ross, G. S., Wims, A. M., and Verdier, P. H., J. Res. Nat. Bur. Stand. (U.S.), 76A, (Phys. and Chem.), No. 2, 156-160 (Mar--Apr. 1972). Paper VIII of this series.

(Paper 76A2-712) 


\title{
The Characterization of Linear Polyethylene SRM 1475
}

\section{Light-Scattering Studies on Polyethylenes in 1-Chloronaphthalene}

\author{
Lois J. Frolen, Gaylon S. Ross, Andrew M. Wims*, and Peter H. Verdier \\ Institute for Materials Research, National Bureau of Standards, Washington, D.C. 20234
}

(December 15, 1971)

\begin{abstract}
Light-scattering measurements have been made on a series of linear polyethylene fractions and a linear polyethylene standard reference material (SRM 1475). All measurements were made in 1chloronaphthalene at $135^{\circ} \mathrm{C}$, and over an angular range from $45^{\circ}$ to $135^{\circ}$. The data were analyzed to obtain the weight average molecular weights, second virial coefficients and root-mean square end-toend distances.
\end{abstract}

Key words: End-to-end distance; light scattering; linear polyethylene; polyethylene fractions; $M_{w}$; second virial coefficient; solution properties.

\section{Introduction}

Several investigators $[1,2]^{1}$ have used the technique of light scattering to obtain weight-average molecular weights, second virial coefficients and radii of gyration for polyethylene in dilute solutions. In this paper, we report the results of light scattering studies on a series of linear polyethylene fractions with molecular weight ranging from about $1.9 \times 10^{4}$ to about $6.9 \times 10^{5}$. The weight-average molecular weights reported here were employed in the calibration of a gel permeation chromatograph used [3] to obtain the molecular weight distribution of Standard Reference Material 1475, Linear Polyethylene. We also report the direct determination of weight-average molecular weight for SRM 1475 by light scattering.

\section{Experimental Procedure}

\subsection{Apparatus}

The light scattering photometer described by McIntyre and Doderer [4] was used for most of the studies reported here. However, a few measurements were made on a modified Brice-Phoenix Photometer (Phoenix Precision Instrument Company, Philadelphia, $\mathrm{Pa}$.). ${ }^{2}$ Consistent results were obtained from the two instruments, and data from both instruments are included in the analysis of results.

* Present address: General Motors Research Laboratory, Warren, Michigan 48092

${ }^{1}$ Figures in brackets indicate the literature references at the end of this paper

${ }^{2}$ Certain commercial equipment, instruments, or materials are identified in this paper in order to adequately specify the experimental procedure. In no case does such identification imply recommendation or endorsement by the National Bureau of Standards, nor does it imply that the material or equipment identified is necessarily the best available for the purpose.
All measurements on polyethylene solutions were made at $135^{\circ} \mathrm{C}$, using a heated cell holder [5] designed and constructed in this laboratory. A schematic drawing of the cell holder is shown in figure 1. It consists of two concentric cylinders wrapped with heating wire, insulated with alternating layers of balsa wood and aluminum foil bonded together with silicone rubber adhesive. A slot, not shown in the figure, extends slightly more than halfway around the oven at the height of the sample cell to provide paths for the in-

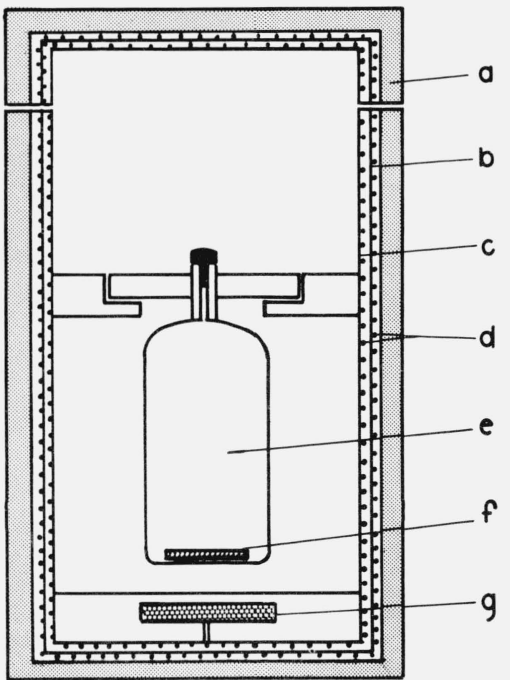

FigURE 1. Schematic drawing of high temperature oven for light scattering cells.

a. Insulation, b. outer cylinder, c. inner cylinder, d. heating wire, e. light scattering cell, $f$ stirring bar, g. rotatable magnet. 
cident, transmitted and scattered light. A small rotatable magnet under the sample cell permits stirring when desired. The scattering cells used with the oven are clear Pyrex cylindrical cells fitted with capillary necks and Teflon stoppers to minimize contamination by dust.

Measurements on polyethylene were made with the outer cylinder heated to $130^{\circ} \mathrm{C}$ and the temperature of the inner cylinder controlled to maintain the sample at $135^{\circ} \mathrm{C}$. No attempt was made to monitor the temperature of the solutions in the light scattering cell while measurements were being taken. However, in preliminary tests, the temperature at various points in the stirred solvent was monitored with thermocouples. The liquid attained a steady temperature of $135^{\circ}$ in 15 minutes and thereafter showed temperature variations of less than $\pm 0.05^{\circ} \mathrm{C}$ during a period of one hour.

A solution of polystyrene in toluene was used as a working standard to calibrate the instrument. Measurements of absolute scattering on the working standard were made at room temperature (about $25{ }^{\circ} \mathrm{C}$ ) in a semi-octagonal sample cell with a clear (unblackened) back surface. The temperature control employed for the higher-temperature measurements on polyethylene was felt to be unnecessary for the room-temperature reference measurements. The oven and cell holder described above were therefore not used for the reference measurements.

\subsection{Preparation of Samples}

The preparation of the linear polyethylene fractions is described in paper VI of this series [6]. The solvent employed was Fisher Reagent Grade 1-chloronaphthalene which was passed through activated 28-200 mesh silica gel before use. Gas chromatographic analysis of the solvent showed less than 0.1 percent observable impurity. Before being filled with solution, the light scattering cells were cleaned with hot chromic acid, rinsed with distilled water, dried in a dust-free atmosphere, and rinsed from three to five times with filtered 1-chloronaphthalene.

Each sample was prepared by adding approximately $10 \mathrm{~cm}^{3}$ of solvent to a weighed amount of polyethylene, stirring at $130-135^{\circ} \mathrm{C}$ until the polyethylene dissolved (usually 1 to $1^{1 / 2} \mathrm{~h}$ ) and weighing the resulting solution. The sample was then filtered as described below into a weighed scattering cell. After light scattering measurements had been taken, second and third concentrations were prepared for measurement by adding approximately $5 \mathrm{~cm}^{3}$ increments of filtered solvent, weighing the scattering cell before and after each addition. Weight per unit volume concentrations were calculated from the weights of solvent and solute, solvent density, and partial specific volume [7] of polyethylene in 1-chloronaphthalene. For some representative samples, the final concentration was checked by evaporating $10 \mathrm{~cm}^{3}$ of the solution and weighing the residue. In all cases, the concentration so obtained agreed with that calculated from the known dilutions to within 1 percent.

The samples were filtered with a heated $40 \mathrm{~cm}^{3}$ hypodermic syringe fitted with a "Swinney Adapter" filter holder (Millipore Corp., Bedford, Mass. 01730). A ball joint sealed to the top of the syringe allowed the rate of filtration to be controlled with nitrogen gas under pressure. The nitrogen pressure was adjusted to give a flow rate of approximately 1 drop per second. Faster flow rates resulted in less clean samples as determined by their erratic scattering at low angles. Two Metricel type, Alpha-6 filter discs with a nominal pore size of $0.4 \mu \mathrm{m}$ (Gelman Instrument Co., Ann Arbor, Mich. 48106) were used for each filtration. These discs had been found to be resistant to 1chloronaphthalene and could be used at temperatures up to $150{ }^{\circ} \mathrm{C}$ without apparent damage. They were rinsed with the material to be filtered before use, and were changed after each filtration.

During filtration, the syringe was heated by placing it in a glass tube wrapped with heating wire and maintained at $135-140^{\circ} \mathrm{C}$. The needle of the syringe was inserted into the capillary neck of the lightscattering cell, and the filtration was carried out in a stagnant air box to minimize contamination by dust.

\subsection{Scattering Measurements}

Scattered intensities were measured at eleven scattering angles ranging from $45^{\circ}$ to $135^{\circ}$. Measurements on SRM 1475 were made at 25 concentrations, in the range from $1.7 \times 10^{-3}$ to $20.8 \times 10^{-3} \mathrm{~g} / \mathrm{cm}^{3}$. Measurements on each of the seven fractions listed in table 1 were-made at six concentrations. The concentrations chosen varied with the molecular weights of the fractions, from a range of $1.8 \times 10^{-2}$ to $5.7 \times 10^{-2}$ $\mathrm{g} / \mathrm{cm}^{3}$ for PE 15 to a range of $0.7 \times 10^{-3}$ to $2.6 \times 10^{-3}$ $\mathrm{g} / \mathrm{cm}^{3}$ for PE 600 . Measurements were also made on pure solvent. The incident illumination in all cases was the mercury green line of wavelength $5461 \AA$, planepolarized with its electric vector perpendicular to the scattering plane.

As mentioned previously, a solution of polystyrene in toluene was used as a working standard. The absolute scattering of the working standard at $90^{\circ}$ was first determined. As each polyethylene solution was measured, the scattered intensity from the working standard at $90^{\circ}$ was also recorded. Thus, the quantity actually obtained was the ratio of the scattering from the solution (or solvent) at each angle to that of the working standard at $90^{\circ}$.

\section{Treatment of the Data}

The use of light scattering to determine molecular weight and size parameters of macromolecules in dilute solution is well established [8]. At sufficiently low concentrations and small scattering angles, the ratio of solution concentration to scattered light intensity may be expanded in a Taylor series in concentration and in the sine of half the scattering angle. For planepolarized monochromatic light scattered through an angle $\theta$, the result for a solution of monodisperse 
material may be expressed in the form [9]:

$$
\frac{K c}{R_{\theta}}=\frac{1}{M}+\frac{h^{2} R_{G}^{2}}{3 M}+2 A_{2} c+\ldots,
$$

with:

$$
\begin{gathered}
K=\left(4 \pi^{2} n^{2} / \lambda_{0}^{4} N_{A}\right)(d n / d c)^{2}\left(1-\cos ^{2} \psi \sin ^{2} \theta\right), \\
R_{\theta}=r^{2}[I(\theta, c)-I(\theta, 0)] /\left(v I_{0}\right),
\end{gathered}
$$

and

$$
h=(4 \pi / \lambda) \sin (\theta / 2)=\left(4 \pi n / \lambda_{0}\right) \sin (\theta / 2),
$$

where

$c$ is solution concentration (weight per unit volume), $M$ is the molecular weight of the solute,

$R_{G}$ is the radius of gyration of the solute,

$A_{2}$ is the second virial coefficient of the solution,

$\lambda_{0}$ is the wavelength in vacuo of the radiation,

$n$ is the index of refraction of the solvent at wavelength $\lambda_{0}$,

$\lambda=\lambda_{0} / n$ is the wavelength of the radiation in the solvent,

$N_{A}$ is Avogadro's number,

$d n / d c$, the so-called differential refractive index, is the derivative (at constant temperature and pressure and in the limit of zero concentration) of solution refractive index with respect to concentration,

$\theta$ is the angle between the incident and scattered wave vectors,

$\psi$ is the angle between the electric vector of the incident radiation and the plane containing the incident and scattered wave vectors,

$I_{0}$ is the intensity of the incident radiation,

$I(\theta, c)$ is the scattered intensity at angle $\theta$ for a solution of concentration $c$,

$r$ is the distance from the scattering center to the point at which the scattered intensity is observed, and

$v=v(n, \theta)$ is the volume of solution from which the scattered radiation is observed.

For the special cases $\psi=\pi / 2$ and $\psi=0$ (so-called vertical and horizontal polarization), the last factor in eq (2) becomes unity and $\cos ^{2} \theta$, respectively. (The usually-quoted result for unpolarized incident radiation is obtained by averaging over all possible values of $\psi$, in which case the factor becomes $\left(1+\cos ^{2} \theta\right) / 2$.)

For a solution of polydisperse material, it can be shown $[10,11]$ that eq (1) still holds at sufficiently small scattering angle and low concentration, provided $M$ is replaced by $M_{w}$, the weight-average molecular weight, $R_{G}^{2}$ is replaced by its $z$-average, $\left\langle R_{G}^{2}\right\rangle_{z}[12]$, and $A_{2}$ is replaced by an "effective" value without simple interpretation [11].

In order to use eqs (1)-(4) to relate observed scattering to molecular parameters, it is necessary to know the functional dependence of the scattering volume, $v$, upon $n$ and $\theta$. For the geometry of our instrument, the scattering volume is inversely proportional to the square of the index of refraction of the material in the scattering cell $[13,14]$. A simple geometrical argument suggests that for scattering angles not too close to $0^{\circ}$ or $180^{\circ}$, the scattering volume should vary as the cosecant of the scattering angle. (The validity of the approximation was established for the present work, in the course of checking the alignment of the instrument, by measurements on fluorescein solutions.) Thus we can write

$$
v(n, \theta)=v_{0} n^{-2} \csc \theta .
$$

Finally, the observed intensities must be corrected for the effects of reflections at the entrances and exits of the scattering cells, as discussed by Kratohvil [15]. When light impinges perpendicularly upon an interface between two regions with indices of refraction $n_{1}$ and $n_{2}$, the fraction $f$ reflected is given by Fresnel's formula: $f=\left[\left(n_{1}-n_{2}\right) /\left(n_{1}+n_{2}\right)\right]^{2}$. In the light-scattering experiment, such interfaces occur at both the inside and the outside surfaces of the walls of the scattering cells. If we make the usual assumption that the difference between the index of refraction of the solution inside the scattering cell and the index of the glass in the cell walls is so small as to cause negligible reflection, we are left with only the interfaces between the cell walls and the air outside the cell to consider. By counting up the various possible paths resulting from multiple reflections of the incident and scattered beams, we can readily show that for a circularly cylindrical scattering cell, the observed intensity $I^{\prime}(\theta, c)$ is related to the "true" intensity $I(\theta, c)$ (i. e., that which would be observed in the absence of reflections) by

$I(\theta, c)=(1-f)^{-2}\left[\left(1+f^{2}\right) I^{\prime}(\theta, c)-2 f I^{\prime}(\pi-\theta, c)\right]$,

where $f=\left[\left(n_{g}-1\right) /\left(n_{g}+1\right)\right]^{2}$, and $n_{g}$ is the index of refraction of the cell wall glass. Equation (6) is in agreement, to first order in $f$, with the approximate result obtained by Kratohvil [15] for this case.

For the semioctagonal cell used to determine absolute scattering by the working standard, only the intensity of the beam scattered through an angle $\theta=\pi / 2$ and the intensity $I_{0}$ of the incident (unscattered) beam need be considered. For right-angle scattering, the light paths for this cell are identical with those for a circularly cylindrical cell, and the special case $I=I^{\prime}$ obtained from eq (6) for $\theta=\pi / 2$ also applies to this cell. For the incident beam, observed after passage through the semioctagonal cell, it can easily be shown that

$$
I_{0}=I_{0}^{\prime}(1+f) /(1-f) .
$$

For the present work, the quantity $R_{\pi / 2, s}=r^{2} I_{s} /\left(v I_{0}\right)$, where we denote by $I_{s}$ the intensity of right-angle scattering from the working standard, was first determined as described by McIntyre [13]. The intensity ratio $I_{s} / I_{0}$ was measured with the use of a set of calibrated filters, and was corrected for reflections as described above. For the semioctagonal cell employed, the quantities $r$ and $v_{0}$ were obtainable from the 
instrument geometry, and the scattering volume $v$ was obtained from eq (5).

For measurements made on the working standard at $90^{\circ}$ in the circularly cylindrical scattering cells, we can use the definition of $R_{\pi / 2, s}$ and eq (5) to write

$$
v_{0} I_{0} / r^{2}=I_{s} n_{s}^{2} / R_{\pi / 2, s},
$$

where $n_{s}$ is the index of refraction of the working standard. With the use of eqs (2)-(6), the left-hand side of eq (1) can be rewritten in the form

$$
\begin{array}{r}
\frac{K c}{R_{\theta}}=\frac{4 \pi^{2} n_{s}^{2} c\left(1-\cos ^{2} \psi \sin ^{2} \theta\right) \csc \theta(d n / d c)^{2}}{\lambda_{0}^{4} N_{A} R_{\pi / 2, s}} \\
\times\left(\frac{I_{s}}{I(\theta, c)-I(\theta, 0)}\right) .
\end{array}
$$

Thus, measurement of the scattering of the solution relative to that of the working standard (the last factor on the right-hand side of eq (9)), together with the value of $d n / d c$ for the solution, yields $K c / R_{\theta}$. Equation (1) may then be used to determine $M_{w}$, $\left\langle R_{G}^{2}\right\rangle_{z}$, and $A_{2}$ from the dependence of $K c / R_{\theta}$ upon $c$ and $\theta$.

In order to extract molecular parameters from experimental values of $K c / R_{\theta}$, we employ the well-known Zimm method [16]. If we plot $K c / R_{\theta}$ as a function of $\sin ^{2}(\theta / 2)+k c$, where $k$ is a constant chosen for convenience, we obtain an array of points through which lines of constant concentration and lines of constant angle can be drawn, as exemplified in figure 2. Extrapolation of each of the constant-concentration lines to zero angle gives a set of points which constitute a plot of $K c / R_{0}$ versus $k c$. According to eq (1), such a plot intersects the $K c / R_{\theta}$-axis at $1 / M_{w}$, with a limiting slope of $2 A_{2} / k$. In the same way, extrapolation of each of the constant-angle lines to zero concentration yields a plot of $\lim _{c \rightarrow 0}\left[K c / R_{\theta}\right]$ versus $\sin ^{2}(\theta / 2)$. Combining eqs (1) and (4), we find:

$$
\lim _{c \rightarrow 0}\left[K c / R_{\theta}\right]=M_{w}^{-1}\left[1+(16 / 3) \pi^{2} \lambda^{-2}\left\langle R_{G}^{2}\right\rangle_{z} \sin ^{2}(\theta / 2)\right] .
$$

The intercept is therefore again $1 / M_{w}$, and the limiting slope is a measure of $\left\langle R_{G}^{2}\right\rangle_{z}$. In the special case of a linear random-coil chain one can estimate the meansquare distance, $\left\langle L^{2}\right\rangle$, between the ends of the chain by using the relation [17] $\left\langle L^{2}\right\rangle=6\left\langle R_{G}^{2}\right\rangle$, although this

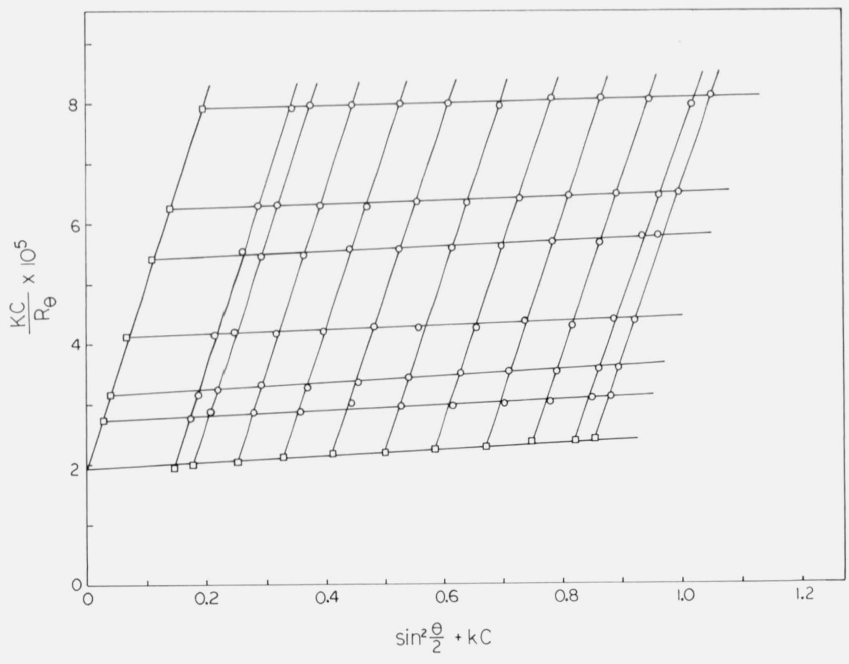

Figure 2. Typical Zimm plot $\left(\mathrm{Kc} / \mathrm{R}_{\theta}\right.$ versus $\left.\sin ^{2}(\theta / 2)+\mathrm{kc}\right)$ obtained for linear polyethylene in 1-chloronaphthalene at $135^{\circ} \mathrm{C}$.

The concentration $c$ is expressed in $\mathrm{g} / \mathrm{cm}^{3}$; the arbitrary constant $k$ was chosen to have a value of $10 \mathrm{~cm}^{3} / \mathrm{g}$. The other symbols are explained in the text. The circles are experimental values; the squares are extrapolations to zero angle at constant concentration and to zero concentration at constant angle.

relation has been established only for chains with Gaussian random-flight statistics.

\section{Results}

The results obtained for the linear polyethylene fractions and for SRM 1475 are summarized in table 1, together with the values of $d n / d c$ used in calculating $K c / R_{\theta}$. For SRM 1475 and the fractions with $M_{w}$ less than 200,000 , measured values [7] of $d n / d c$ were used. For fractions with $M_{w}$ greater than 200,000, measured values of $d n / d c$ were not available, but measurements on the lower-molecular-weight fractions appeared to suggest that by this point, $d n / d c$ had reached a constant value of $-0.188 \mathrm{ml} / \mathrm{g}$ independent of molecular weight. This value of $d n / d c$ was therefore used in calculating $K c / R_{\theta}$ for the fractions of $M_{w}$ above 200,000 .

Values of $K c / R_{\theta}$ for each fraction and for SRM 1475 were analyzed by the Zimm technique, as described in the preceding section. In all cases, plots of $K c / R_{\theta}$ versus $\sin ^{2}(\theta / 2)+k c$ were found to be linear throughout the entire angular range. A typical plot, obtained for SRM 1475, is shown in figure 2. For clarity, the plot

\begin{tabular}{|c|c|c|c|c|}
\hline Sample & $d n / d c, \mathrm{ml} / \mathrm{g}$ & $M_{w} \times 10^{-3}, \mathrm{~g} / \mathrm{mol}$ & $A_{2} \times 10^{3}, \mathrm{~mol} \cdot \mathrm{cm}^{3} / \mathrm{g}^{2}$ & $\left\langle L^{2}\right\rangle^{1 / 2} \times 10^{-3}, \AA$ \\
\hline 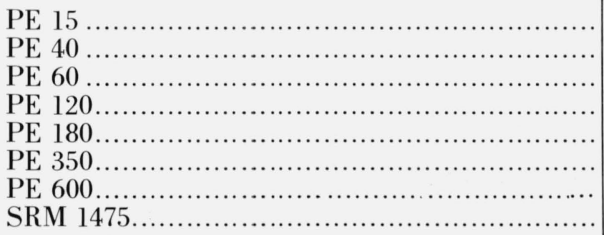 & $\begin{array}{r}-0.193 \\
-.191 \\
-.190 \\
-.188 \\
-.188 \\
-.188 \\
-.188 \\
-.193\end{array}$ & $\begin{array}{l}19.1 \pm 2.4 \\
49.4 \pm 2.0 \\
82.2 \pm 7.1 \\
170 \pm 16 \\
210 \pm 30 \\
520 \pm 42 \\
688 \pm 67 \\
52.0 \pm 2.0\end{array}$ & $\begin{array}{l}1.9 \\
1.6 \\
1.6 \\
1.4 \\
1.2 \\
1.3 \\
1.2 \\
1\end{array}$ & $\begin{array}{r}0.4 \\
.6 \\
.6 \\
.7 \\
.9 \\
1.4 \\
2.1\end{array}$ \\
\hline
\end{tabular}

TABLE 1. Weight-average molecular weights $\mathrm{M}_{\mathrm{w}}$, second virial coefficients $\mathrm{A}_{2}$, and rms end-to-end lengths $\left\langle\mathrm{L}^{2}\right\rangle^{1 / 2}$, for linear polyethylenes in 1-chloronaphthalene at $135^{\circ} \mathrm{C}$.

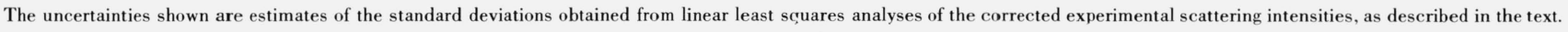


shows the data for only six of the 25 concentrations actually employed. The lack of downward curvature in the plots suggests that the samples were adequately cleaned [18].

The linear extrapolations necessary to obtain $M_{w}$, $\left\langle R_{G}^{2}\right\rangle_{z}$, and $A_{2}$ were carried out by unweighted linear least-squares analyses. The results are given in table 1 , together with estimates of the standard deviation in $M_{w}$ inferred from the least-squares analyses. The values of the rms end-to-end length, $\left\langle L^{2}\right\rangle^{1 / 2}$, given in table 1 were obtained from the values found for $\left\langle R_{C_{i}}^{2}\right\rangle_{z}$ by use of the approximate relation $\left\langle L^{2}\right\rangle=6$ $\left\langle R_{G}^{2}\right\rangle$, as described in the preceding section. It is clear from the lack of smoothness in the variation of $A_{2}$ and $\left\langle L^{2}\right\rangle^{1 / 2}$ with molecular weight that they are to be regarded as no more than crude estimates. Estimates of the standard deviations in $\left\langle R_{G i}^{2}\right\rangle_{z}$ and $A_{2}$ from the least-squares analyses were unrealistically low (typically, about 5 per cent for $A_{2}$ and $50-100 \AA$ for $\left.\left\langle L^{2}\right\rangle^{1 / 2}\right)$, and are therefore not shown in the table. Values of $\left\langle R_{G i}^{2}\right\rangle_{z}$ and $A_{2}$ were not calculated for SRM 1475.

\section{References}

[1] DeLaCusta, M. O., and Billmeyer, F. W.. Jr., J. Polymer Sci. A1, 1721 (1963).

[2] Chiang, R., J. Phys. Chem. 69, 1645 (1965).

[3] Ross, G. S., and Frolen, L. J.. J. Res. Nat. Bur. Stand. (U.S.), 76A (Phys. and Chem.), No. 2, 163-170 (Mar.-Apr. 1972). Paper X of this series.
[4] McIntyre, D., and Doderer, G. C., J. Res. Nat. Bur. Stand. (U.S.), 62, 153 (1959).

[5] Wims, A., and Ross, G. S., unpublished work.

[6] Christensen, R. G., J. Res. Nat. Bur. Stand. (U.S.), 76A, (Phys. and Chem.), No. 2, 149-150 (Mar--Apr. 1972). Paper VI of this series.

[7] Wagner, H. L., J. Res. Nat. Bur. Stand. (U.S.), 76A, (Phys. and Chem.), No. 2, 151-155 (Mar.-Apr. 1972). Paper VII of this series.

[8] See, for example, Kerker, M., The Scattering of Light (Academic Press, New York, 1969); Tanford, C., Physical Chemistry of Macromolecules, John Wiley and Sons, New York, 1961; Flory, P. J., Principles of Polymer Chemistry (Cornell University Press, Ithaca, New York, 1953).

[9] The notation used here is essentially that used by Kerker (op. cit., Ch. 8), but is written for plane-polarized incident radiation rather than for unpolarized radiation.

[10] Kerker, op. cit., Ch. 8.

[11] Fujita, H., Mathematical Theory of Sedimentation Analysis, p. 268 f. (Academic Press, New York, 1962).

[12] We define the $z$-average of the square of the radius of gyration of a polydisperse material as

$$
\left\langle R_{G i}^{2}\right\rangle_{z}=\sum_{i} n_{i} M_{i}^{2} R_{G i}^{2} / \sum_{i} n_{i} M_{i}^{2},
$$

where $n_{i}$ is the number of molecules of the $i$-th component, of molecular weight $M_{i}$ and radius of gyration $R_{G i}$.

[13] McIntyre, D., J. Res. Nat. Bur. Stand. (U.S.), 68A, (Phys. and Chem.) 87 (1964).

[14] Herman, J. J. and Levinson, S., J. Opt. Soc. Am. 41, 460 (1951).

[15] Kratohvil, J. P., J. Colloid and Interface Science 21, 498 (1966).

[16] Zimm, B. H., J. Chem. Phys. 16, 1099 (1948).

[17] See, for example, Flory, P. J.. op. cit.

[18] Muus, L. T., and Billmeyer, F. W., Jr., J. Am. Chem. Soc. 79, 5079 (1957).

(Paper 76A2-713) 